\title{
MicroRNAs miR-26a, miR-26b, and miR-29b accelerate osteogenic differentiation of unrestricted somatic stem cells from human cord blood
}

Hans-Ingo Trompeter ${ }^{1 *}{ }^{*}$, Janine Dreesen ${ }^{1 \dagger}$, Eugenie Hermann ${ }^{1}$, Katharina M Iwaniuk ${ }^{1}$, Markus Hafner ${ }^{2}$, Neil Renwick', Thomas Tuschl ${ }^{2}$ and Peter Wernet ${ }^{1}$

\begin{abstract}
Background: MicroRNAs are a population of short non-coding RNAs with widespread negative regulatory impact on mRNA translation. Unrestricted somatic stem cells (USSC) are a rare population in human cord blood that can be induced into cells representative of all three germinal layers. Here we analyzed the functional impact of miRNAs on the osteogenic differentiation in USSC.

Results: Gene expression profiling identified 20 microRNAs that were consistently upregulated during osteogenic differentiation of two different USSC cell lines (SA5/73 and SA8/25). Bioinformatic target gene prediction indicated that among these microRNAs, miR-10a, -22, $-26 a,-26 b$, and -29b recognize transcripts that encode a set of proteins inhibiting osteogenesis. We subsequently verified osteo-inhibitory CDK6, CTNNBIP1, HDAC4, and TOB1 and osteopromoting SMAD1 as targets of these microRNAs. In Western blot analyses demonstrated that endogenous levels of CDK6 and HDAC4 were downregulated during osteogenic differentiation of USSC and reduced following ectopic expression of miR-26a/b and miR-29b. In contrast, endogenous expression of SMAD1, targeted by miR-26a/b, was unaltered during osteogenic differentiation of USSC or following ectopic expression of miR-26a/b. Functional overexpression analyses using microRNA mimics revealed that miR-26a/b, as well as miR-29b strongly accelerated osteogenic differentiation of USSC as assessed by Alizarin-Red staining and calcium-release assays.

Conclusions: miR-26a/b and miR-29b are upregulated during osteogenic differentiation of USSC and share target genes inhibiting osteogenesis. Furthermore, these microRNAs accelerate osteogenic differentiation, likely mediated by osteo-inhibitory proteins such as CDK6 and HDAC4.
\end{abstract}

Keywords: Cord blood stem cells, Osteogenic differentiation, MicroRNA expression, MicroRNA function, MicroRNA target identification

\section{Background}

microRNA (miRNA)-mediated translational repression is an important regulatory mechanism in multiple cellular processes. miRNAs are a subpopulation of small RNAs, averaging 22 nucleotides in length, which inhibit translation through sequence-specific binding to target sites within the 3'-UTRs of mRNAs. Following transcription, miRNAs are processed in a two-step mechanism involving the RNAses DROSHA and DICER [1,2] and subsequently

\footnotetext{
* Correspondence: trompeter@itz.uni-duesseldorf.de

${ }^{\dagger}$ Equal contributors

'University Düsseldorf, Medical Faculty, Institute for Transplantation Diagnostics and Cell Therapeutics (ITZ), Düsseldorf D-40225, Germany Full list of author information is available at the end of the article
}

integrated into the RNA-induced silencing complex [3,4], thereby unfolding their regulatory potential to regulate mRNAs [5-7]. Exhibiting stage- and tissue-specific expression patterns during development [8,9], miRNAs not only function as key regulatory molecules in multiple cellular processes including apoptosis [10,11], cancer [12], proliferation [13], development [14], and differentiation [15] but also control stemness and pluripotency of embryonic stem cells e.g. by repressing pluripotency factors OCT4, SOX2 and KLF4 [16].

Osteogenesis is a highly coordinated process involving transcription factors, such as RUNX2 and OSTERIX $[17,18]$, BMP2, and other factors, that drive committed

\section{Biomed Central}


stem cells toward fully differentiated osteocytes (reviewed in [19-21]). Osteogenesis is promoted through several signalling pathways, including $\mathrm{WNT} / \beta$-catenin, BMP, JAK/STAT, and MAPK [22-27]. Several miRNAs modulate osteogenic differentiation: miR-125b negatively regulates osteoblastic differentiation through targeting VDR, ErbB2, and Osterix [28,29]; miR-133 (targeting RUNX2) and miR-135 (recognizing SMAD5) inhibit differentiation of mouse osteoprogenitors [30]; miR-26a and miR-29b facilitate osteogenic differentiation of human adipose tissue-derived stem cells (hADSCs), and positively modulate mouse osteoblast differentiation [31,32]. Multiple other miRNAs, including miR-9, -17, -27, -30, -96, -106, $138,-181,-182,-320$, and -326 , have been linked to osteogenesis [30].

Unrestricted somatic stem cells (USSC) are a rare CD45-negative population in human cord blood [33]. These cells can be discriminated from CB-MSC and BMMSC by their HOX expression pattern which resembles that of $\mathrm{H} 9$ embryonic stem cells [34]. Adherently-growing in vitro USSC can be induced to cells representative of all three germinal layers on a clonal level [35] and have been successfully reprogrammed to a pluripotent ES-like state [36]. Undergoing miRNA-supported cell cycle arrest, USSC can be differentiated into cells of neural lineage with miRNAs acting as network-like regulators [37-39]. USSC also differentiate into functional hepatic-like cells $[40,41]$ as well as along osteogenic and chondrogenic lineages [33]. Upon induction with dexamethasone, ascorbic acid, and $B$-glycerol phosphate (DAG), USSC differentiate into osteoblasts as evidenced by calcium phosphate deposition, bone-specific ALP-activity, increase in $\mathrm{Ca}^{2+}$-release, and expression of the osteogenic marker proteins osteocalcin, osteopontin, bone sialo-protein, and collagen type I [33]. Bony reconstitution was observed following implantation of USSC into nude rat femurs [33]. Beside their differentiation potential, USSC also fulfil regenerative functions in acute spinal cord trauma [42].

Here we analyzed the impact of miRNAs on osteogenic differentiation of USSC. We identified a set of miRNAs upregulated upon induction of osteogenesis, co-ordinately regulating a distinct set of genes known to inhibit osteogenesis. Among these inhibitors, CDK6, CTNNBIP1, HDAC4, TGFB3, and TOB1 were experimentally identified as targets of miR-26a, miR-26b, and miR-29b. These miRNAs were functionally identified as accelerators of osteogenic differentiation of USSC.

\section{Results}

Differential miRNA expression during osteogenic differentiation of USSC

To assess the impact of miRNAs on osteogenic differentiation of USSC we studied two USSC lines (USSC SA5/73 and USSC SA8/25) that were induced to osteogenic differentiation using DAG as described [33]. As strong calcification of USSC during osteogenic differentiation impacts RNA isolation, we restricted our analyses to day 7 of differentiation. miRNA expression profiles of native and day 7 osteo-differentiated USSC were analyzed using the RT-PCR-based TaqMan Assay (Pool A) covering 377 miRNAs [43]. In SA5/73, 220 miRNAs were expressed and 124 miRNAs were upregulated by a factor $\geqq 2$ in differentiated cells. In SA8/25, 225 miRNAs were expressed and 196 miRNAs were upregulated during osteogenic differentiation. Interestingly, only 30 miRNAs were commonly upregulated in both USSC lines. In follow-up analyses we focused on 20 of these microRNAs (Figure 1), which were not only upregulated by a factor $\geqq 2$ but also present at high expression levels $(<\mathrm{Ct} 26)$ in differentiated USSC. We omitted those upregulated miRNAs that were weakly expressed in differentiated USSC due to their expected minor biological impact. Among the most prominently expressed miRNAs were miR-10a, miR-152, miR22, miR-26a/b, miR-29b, miR-30b/c, miR-345, and miR532-5p. Complete miRNA expression data from USSC SA5/73 and SA8/25 osteogenic differentiation experiments are presented in Additional file 1.

\section{Bioinformatic target gene predictions}

To investigate the biological impact of our selected set of 20 miRNAs, we computationally identified miRNA targets using the DIANA miRGen target gene prediction software [44], which combines the prediction results of several web-based algorithms (TargetScan, PicTar-4, PicTar-5, miRanda, DIANA microT). This approach resulted in an extensive list of putative targets ( $>10^{4}$ genes), many of which were recognized by more than one of our 20 miRNAs. As our study is focused on miRNAs that are upregulated during osteogenic differentiation, we reasoned that their biological impact should be posttranscriptional downregulation of proteins inhibiting osteogenic differentiation. We thus filtered our list of putative targets using the Gene Ontology (GO) terms function implemented in the DAVID database, applying search terms like "bone" and "osteo". Table 1 presents an overview of 21 proteins inhibiting osteogenic differentiation that are putatively recognized by our set of 20 miRNAs. Consistent with the view that miRNAs regulate networks [38], Table 1 demonstrates target gene redundancy: certain proteins were predicted to be targeted by more than one miRNA and other miRNAs (e.g. miR-29b) putatively regulate up to 11 proteins (Table 1 ).

Computational predictions indicated that the BMP-2 antagonist CDK6 [45-47] was recognized by six miRNAs (miRs-101, -137, -22, -26a, -26b, and -29b); CTNNBIP1 (also termed ICAT), an inhibitor of 3 -catenin mediated transcription [48], was likely regulated by five miRNAs (miRs-10a, -192, -26a, -26b, and -29b); and Runx2 corepressor HDAC4 [49] was a putative target of four 


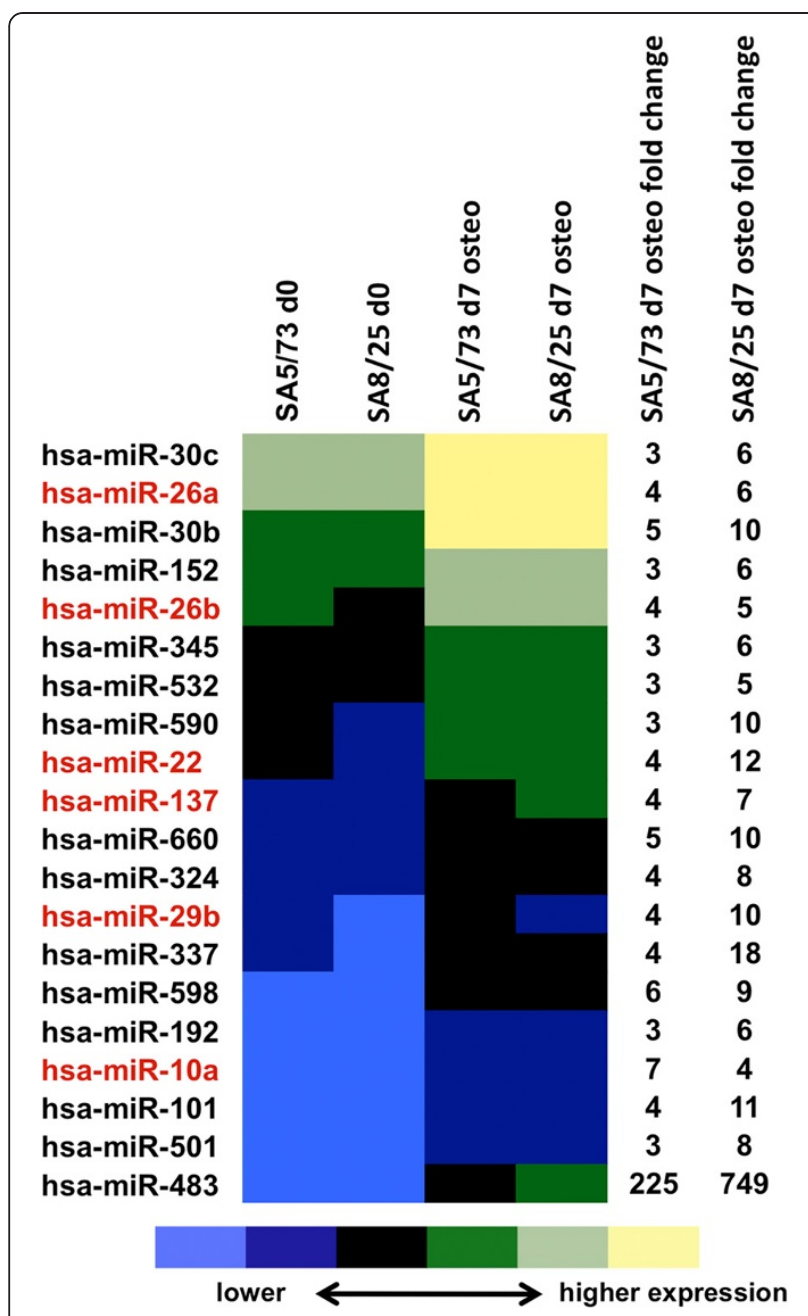

Figure 1 Differential miRNA expression during DAG-mediated osteogenic differentiation of USSC lines SA5/73 and SA8/25. The heat map shows common upregulation of 20 miRNAs in both cell lines as measured by qRT-PCR, together with the fold changes $\left(2^{- \text {ddCt }}\right)$ of miRNA expression in DAG-induced USSC at day 7 of osteogenic differentiation compared to the native cells. MicroRNAs highlighted in red were selected for further studies. Full miRNA expression data are presented in Additional file 1.

miRNAs (miRs-10a, -22, -29b, and -345). Additional putative osteogenesis-inhibiting target proteins included DUSP2 [50], TOB1 [51], TGFB3 [52,53], and SMAD6 [54] (see Table 1 for target predictions). Interestingly, miR-26a and miR-26b were also predicted to regulate SMAD1, a positive regulator of osteogenic differentiation [55].

The most redundant miRNA-target network involved $\mathrm{miR}-26 \mathrm{a} / \mathrm{b}$ and miR-29b and, to a lesser extent, miR-22, miR-10a, and miR-137 (Table 1); subsequent analyses focused on these six miRNAs. To avoid errors in measuring the expression of highly homologous miR-26a and -26b, we verified our TaqMan miRNA expression data from USSC SA5/73 and SA8/25 (Figure 1) in native USSC lines
SA5/73, SA8/25, SA8/77 and SA4/101 and in (day 7) osteo differentiated SA8/77 and SA4/101, using an established small RNA sequencing method [56,57]. miR-26a and miR26b expression was confirmed in all native USSC lines and both miRNAs were upregulated in differentiated SA8/77 and SA4/101 lines (Additional file 1).

\section{Experimental validation of predicted miRNA targets}

Next, we experimentally verified miRNA regulation of selected targets (Table 1) using an established target validation assay [38,39]. Among these putative targets, CDK6, CTNNBIPI, TOB1, and HDAC4 contained the most predicted miRNA binding sites, whereas DUSP2, TGFB3, and SMAD6 each contained a solitary putative miR-29b target site. PCR amplification products representing the 3 -UTR of target genes were cloned at the 3 -end of the firefly-ORF of dual luciferase (firefly and renilla) vector pmirGLO. Based on the patterns of predicted miRNA binding sites on individual $3^{\prime}$-UTRs (see Additional file 2 for details), we devised the following cloning strategy for target validation: CDK6 3'-UTR (10235 bp) was cloned as two subfragments ranging from bases 147-4275 (CDK6-1) and 5825-9997 (CDK6-2); CTNNBIP1 (2442 bp) and TGFB3 (1088 bp) 3'-UTRs were covered by 1094bp and 277 bp fragments respectively. The HDAC4 3'-UTR (4933 bp) was represented by a 964 bp PCR-fragment (HDAC4-1) and two additional $65 \mathrm{bp}$ and $57 \mathrm{bp}$ double-stranded oligonucleotides (HDAC4-O1, -O2) covering single miRNA binding sites. Using oligonucleotides instead of longer $3^{\prime}$ UTR fragments is well described in the literature (e.g. see [58]). TOB1, DUSP2, SMAD1, and SMAD6 3'UTRs were respectively represented by double-stranded oligonucleotides of $65 \mathrm{bp}, 58 \mathrm{bp}, 37 \mathrm{bp}$, and $116 \mathrm{bp}$. In addition, an oligonucleotide pair with mutated seed sequences was used for TOB1.

Pairs of pmirGLO and pmirGLO/3'-UTR were cotransfected into HEK293T cells with the appropriate miRNAmimic (Dharmacon) to assess the activity of a specific miRNA on a given $3^{\prime}$-UTR. Figures $2 \mathrm{~A}$ and $2 \mathrm{~B}$ depict renilla-normalized firefly activities measured from cotransfections of each mimic miR-10a, -22, -26a, -26b, -29b , and -137 with pmirGLO compared to co-transfections of these mimics with pmirGLO/CDK6-1-3'-UTR (Figure 2A) and pmirGLO/CDK6-2-3'-UTR (Figure 2B) respectively. The percentage reduction of relative firefly activities in pmirGLO/3' - UTR + mimic compared to activities of pmirGLO + mimic transfections correlate with miRNA activity on the given $3^{\prime}$-UTR. Here we identified strong interactions between CDK6-2 and miR-26a and miR-26b and moderate interactions with miR-29b. miR-22 and miR-29b interacted with fragment CDK6-1.

Figure 3 summarizes the results of experimental validations from all 22 predicted miRNA-target interactions: CDK6 was targeted by miR-22, miR-26a, miR-26b, 
Table 1 Bioinformatic target predictions for the subset of $\mathbf{2 0}$ microRNAs upregulated in osteogenic differentiation of USSC

\begin{tabular}{|c|c|c|c|c|c|c|c|c|c|c|c|c|c|c|c|c|c|c|c|c|c|}
\hline & & & & & & & & & & & hsa-n & & & & & & & & & & \\
\hline Protein & Total & 101 & $10 a$ & 137 & 152 & 192 & 22 & $26 a$ & $26 b$ & $29 b$ & $30 \mathrm{~b}$ & $30 c$ & $\begin{array}{c}324- \\
3 p\end{array}$ & 337 & 345 & 483 & 501 & 532 & 590 & 598 & 660 \\
\hline CDK6 & 6 & $x$ & & $x$ & & & $x$ & $x$ & $x$ & $x$ & & & & & & & & & & & \\
\hline CTNNBIP1 & 5 & & $x$ & & & $x$ & & $x$ & $x$ & $\mathrm{x}^{*}$ & & & & & & & & & & & \\
\hline AHSG & 4 & & & & & & & & & $x$ & & & $x$ & & & & & $x$ & & & $x$ \\
\hline HDAC4 & 4 & & $x$ & & & & $x$ & & & $x^{*}$ & & & & & $x$ & & & & & & \\
\hline CHRD & 3 & & & & & & $x$ & & & & & & & $x$ & & $x$ & & & & & \\
\hline COL1A1 & 3 & & & & & & & $x$ & $x$ & $x$ & & & & & & & & & & & \\
\hline SOX2 & 3 & & & & & & & $x$ & $x$ & & & & & & & & & & $x$ & & \\
\hline COL4A2 & 2 & & & & & & & $x$ & & $x^{*}$ & & & & & & & & & & & \\
\hline DUSP2 & 2 & & & & & & & & & $\mathrm{x}^{*}$ & & & & & & & & & & & $x$ \\
\hline HIPK2 & 2 & & & & & & & $x$ & $x$ & & & & & & & & & & & & \\
\hline$\overline{N O G}$ & 2 & & & & $x$ & $x$ & & & & & & & & & & & & & & & \\
\hline SKI & 2 & & & & & & & & & $x$ & & & & & & & & & $\mathbf{x}$ & & \\
\hline SMAD7 & 2 & $x$ & & & & & $x$ & & & & & & & & & & & & & & \\
\hline SOSTDC1 & 2 & & & & & & & $x$ & $x$ & & & & & & & & & & & & \\
\hline STATH & 2 & $x$ & & $x$ & & & & & & & & & & & & & & & & & \\
\hline TGFB3 & 2 & & & & & $x$ & & & & $x^{*}$ & & & & & & & & & & & \\
\hline TOB1 & 2 & & & & & & & $x$ & $x$ & & & & & & & & & & & & \\
\hline ACVR2A & 1 & & & & & $x$ & & & & & & & & & & & & & & & \\
\hline AREG & 1 & & & & & & & & & & & & & & $x$ & & & & & & \\
\hline COL5A3 & 1 & & & & & & & & & $x$ & & & & & & & & & & & \\
\hline SMAD6 & 1 & & & & & & & & & $x$ & & & & & & & & & & & \\
\hline
\end{tabular}

Bioinformatic target predictions for the subset of 20 miRNAs upregulated in osteogenic differentiation of USSC on osteo-inhibitory proteins: miR-26a, -26b, and -29b were experimentally assessed for impact on proteins denoted in bold. The second column ("Total") illustrates the number of miRNAs from the analyzed set that targets an individual protein. Predictions with an asterix were already validated in the literature.

and miR-29b; CTNNBIP1 was regulated by miR-10a and miR-29b; SMAD1 and TOB1 were both recognized by miR-26a and miR-26b; and HDAC4 was targeted by miR29b. Validations for DUSP2, SMAD6 and TGFB3 failed to give strongly positive results, with TGFB3 only weakly affected by miR-29b. Detailed data for all experimental validation studies are presented in Additional file 2. In summary, we identified osteo-inhibitory targets for miR10a, miR-22, miR-26a, miR-26b, and miR-29b with the highest targeting impact resulting from miR-26a, miR-26b, and miR-29b expression.

Target gene expression analysis and impact of regulating microRNAs

As the availability of USSC lines SA5/73 and SA8/25 became limited in the course of our study, we focused on the newer USSC lines 86b and 77 for target gene expression analyses. Using qPCR, we analyzed transcript expression of validated targets CDK6, HDAC4, CTNNBIP1, SMAD1, and TOB1 during osteogenic differentiation of USSC line $86 \mathrm{~b}$ at time points day 0 (native cells), and days 7 and 12 post DAG induction. Figure 4 demonstrates that
CDK6, HDAC4, SMAD1, and CTNNBIP1 were all steadily downregulated at days 7 and 12 compared to day 0 . HDAC4 was downregulated at day 7 , followed by a slight increase in expression at day 12, albeit weaker than at day 0 . We were unable to identify TOB1 transcripts in USSC. These results indicate inverse transcriptional regulation of miRNAs and target-mRNAs inhibiting osteogenic differentiation of USSC.

As miRNAs downregulate their targets on a posttranscriptional level, we also analyzed HDAC4, CDK6, and SMAD1 protein expression during osteogenic differentiation (up to day 12) of USSC $86 \mathrm{~b}$ and in response to ectopic expression of miR-26a, miR-26b, and miR-29b in native USSC86b.

As seen in Figure 5A, HDAC4 was weakly expressed in native USSC 86b and downregulated by a factor 5 in day 9 osteo-differentiated USSC 86b, thereby matching our qPCR results (Figure 4). The HDAC4 protein level was also reduced following transfection with miR-29b (Figure 5B).

CDK6 behaved differently on the protein level; this protein was initially upregulated at day 7 of osteogenic differentiation in USSC 86b, and slightly downregulated at day 


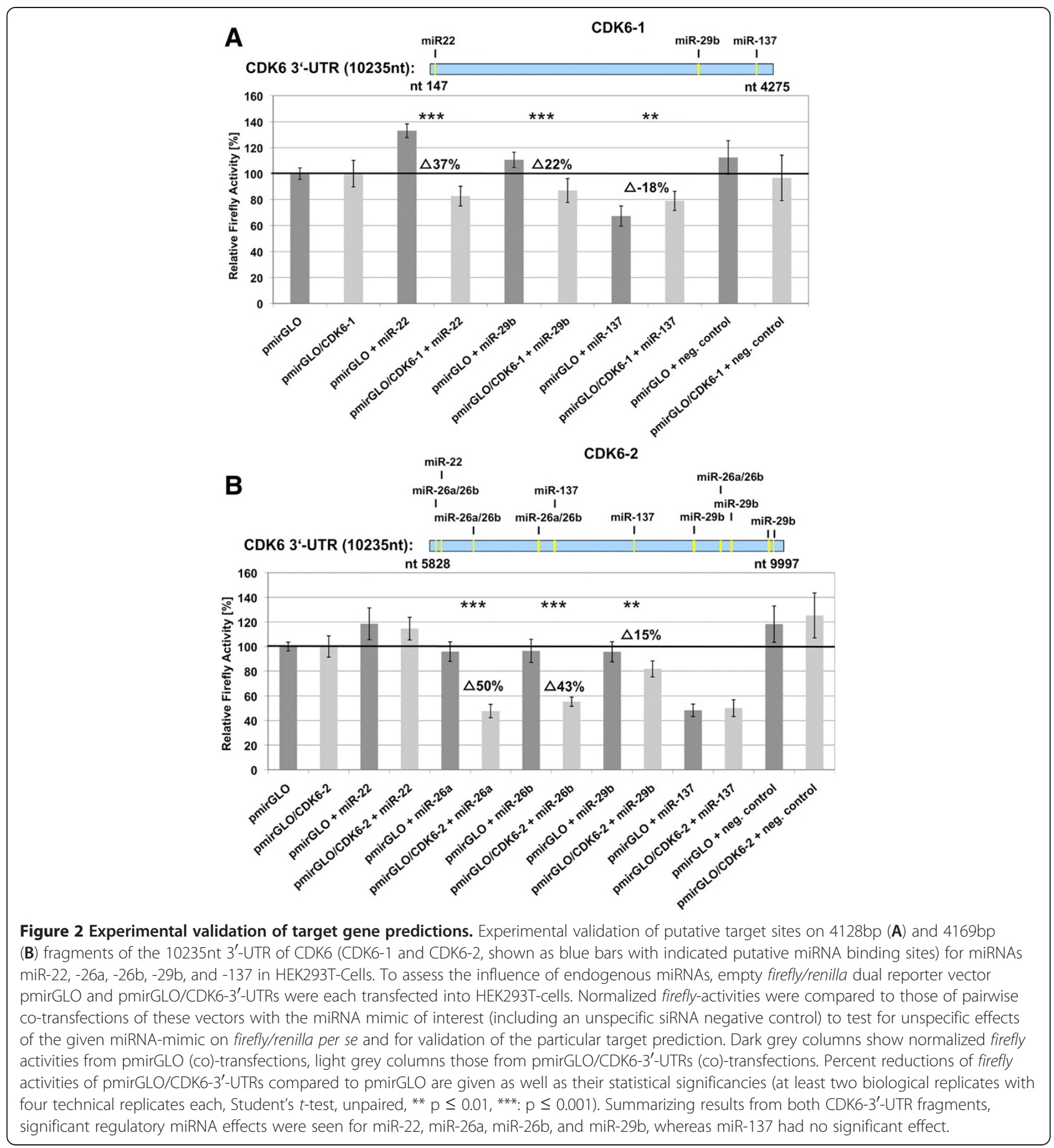

12 although still more abundant than in native cells (Figure 5C). To further examine this unexpected result, we tested an additional USSC line (USSC 77), which yielded the same dynamic CDK6 expression pattern (Figure 5C). Upon independent transfection with (i) an equimolar mixture of miR-26a and miR-26b mimics (both miRNAs share their seed sequence and differ in only two nucleotides) and (ii) with miR-29b mimics, CDK6 protein abundance was reduced compared to native and negative control cells $48 \mathrm{~h}$ after transfection (Figure 5D). As with HDAC4, our results confirm that miR-26a, miR-26b, and miR-29b target CDK6.

Interestingly, SMAD1 expression remained unchanged at day 9 post DAG induction compared to native USSC 86b (Figure 5E) and was not affected by transfection with miR-26a and miR-26b mimics (Figure 5F). We were unable to detect the weakly transcribed CTNNBIP1 with any of several established antibodies (data not shown). 


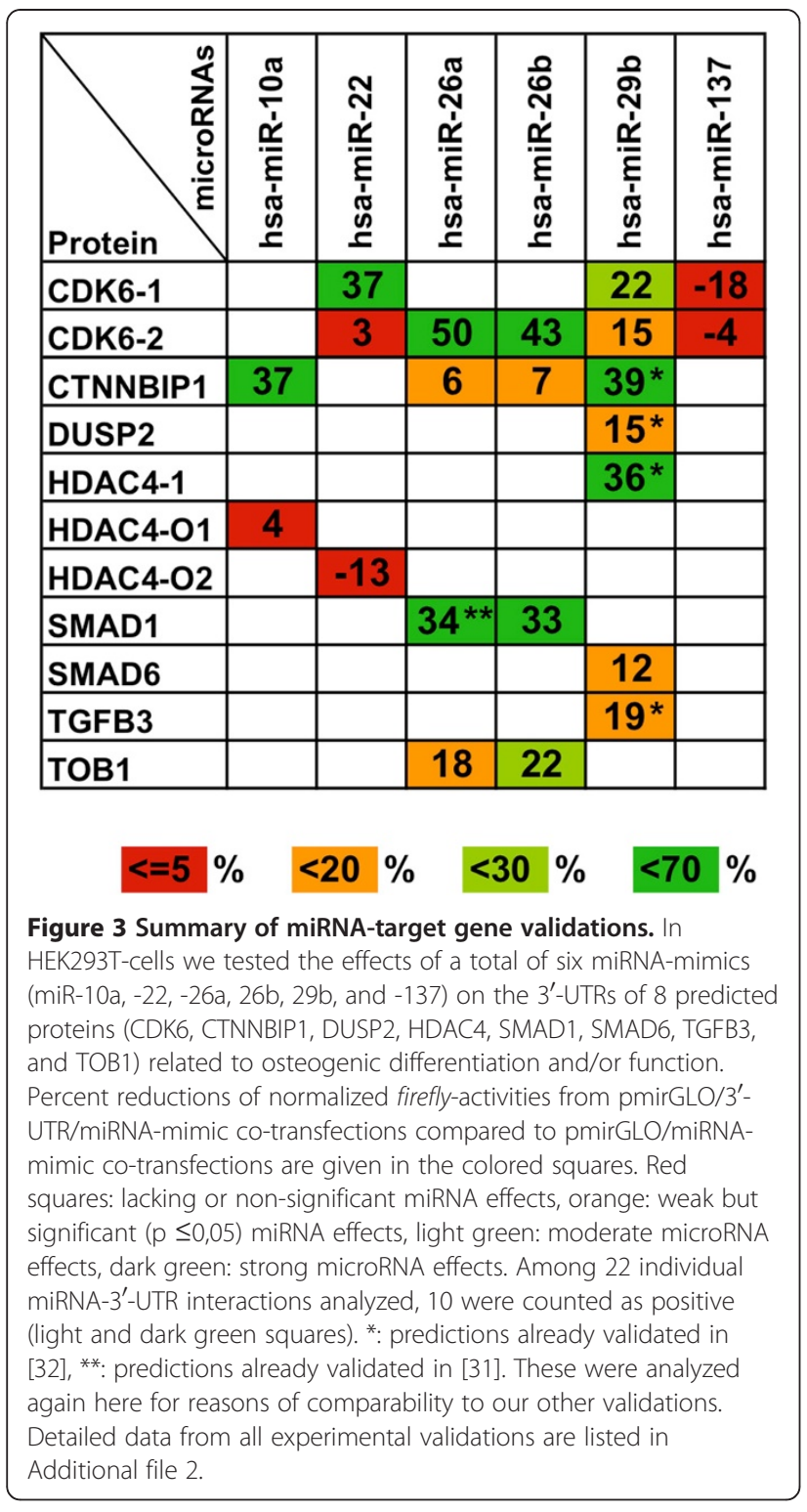

\section{Functional impact of miR-26a/b and miR-29b on osteogenic differentiation of USSC}

Our experimental target validations indicate that miR26a, miR-26b, and miR-29b likely have the strongest impact on osteogenic differentiation of USSC by reducing osteo-inhibitory CDK6 and HDAC4 proteins. We thus tested whether overexpression of $\mathrm{miR}-26 \mathrm{a} / \mathrm{b}$ and $\mathrm{miR}$ 29b using miRNA mimics influences DAG-induced osteogenic differentiation. USSC SA5/73 and USSC 86b were each transfected with (i) a small unspecific negative control RNA, (ii) an equimolar batch of miR-26a and miR-26b, (iii) miR-29b, and (iv) an equimolar batch of miR-26a, miR-26b, and miR-29b mimics (SA5/73 only), each followed by DAG induction. Osteogenic differentiation was assessed by alizarin-red staining and calcium release at day 7 (both USSC lines).
As seen in Figures 6A and 6B, both USSC lines started to differentiate at day 7 post DAG induction. Transfection of negative control RNA did not substantially influence alizarin-red staining in both USSC SA5/73 (Figure 6A) and USSC 86b (Figure 6B). In contrast, miR-26a/b-mimic transfected cells of both USSC lines showed significantly increased staining (Figures 6A and 6B). Transfection with miR-29b-mimic also resulted in accelerated osteogenic differentiation of both lines (Figures 6A and 6B). Transfection of USSC SA5/73 with miR-26a/miR-26b/miR-29b mimics further increased differentiation (Figure 6A).

The finding that miR-26a, miR-26b, and miR-29b accelerated osteogenic differentiation of USSC was further supported by calcium release assays performed in DAGinduced USSC SA5/73 and 86b at days 0 and 7 of osteogenic differentiation. As seen in Figures 7A and 7B, calcium release increased upon transfection with $\mathrm{miR}-26 \mathrm{a} / \mathrm{b}$ and miR-29b as compared to negative-control transfected and untransfected USSC SA5/73 (Figure 7A) and USSC 86b (Figure 7B). Transfection of SA5/73 with the miR-26a/miR$26 \mathrm{~b} / \mathrm{miR}-29 \mathrm{~b}$ batch showed even higher calcium release, compared to miR-26a/miR-26b and miR-29b transfections alone (Figure 7A).

\section{Discussion}

USSC are primary cells from human cord blood and are available in limited amounts from different patient sources. In general, USSC cell lines, such as SA5/73, SA8/25, 86b, and 77 , are capable of comparable osteogenic differentiation as assessed by alizarin-red staining (data not shown). During osteogenic differentiation, only 30 miRNAs were commonly upregulated in two USSC lines (SA5/73 and SA8/25), although 124 and 196 miRNAs were respectively upregulated in each cell line. However, as expected for target-redundant miRNA networks, evaluation of commonly upregulated miRNAs revealed multiple bioinformatically osteo-inhibitory target genes.

miRNA expression profiling followed by target validation indicated that miR-26a, miR-26b, and miR-29b had the highest impact on osteogenic differentiation in our USSC lines. In the mouse osteoblast model, miR-29b is a positive regulator of osteogenic differentiation, able to increase differentiation on ectopic expression, with HDAC4, TGFB3, ACVR2A, CTNNBIP1 and DUSP2 as validated targets [32]. Here we show a comparable function for miR-29b in osteogenic differentiation of human somatic stem cells confirming human CTNNBIP1 and HDAC4 as miR-29b targets in our HEK293T-cell based validation assay. CTNNBIP1 was also regulated by miR-10a and CDK6 [45] was targeted by miR-22, miR-26a, miR-26b and miR-29b.

miR-26a modulates late osteogenic differentiation of hADSC through SMAD1 targeting [31] and we showed 


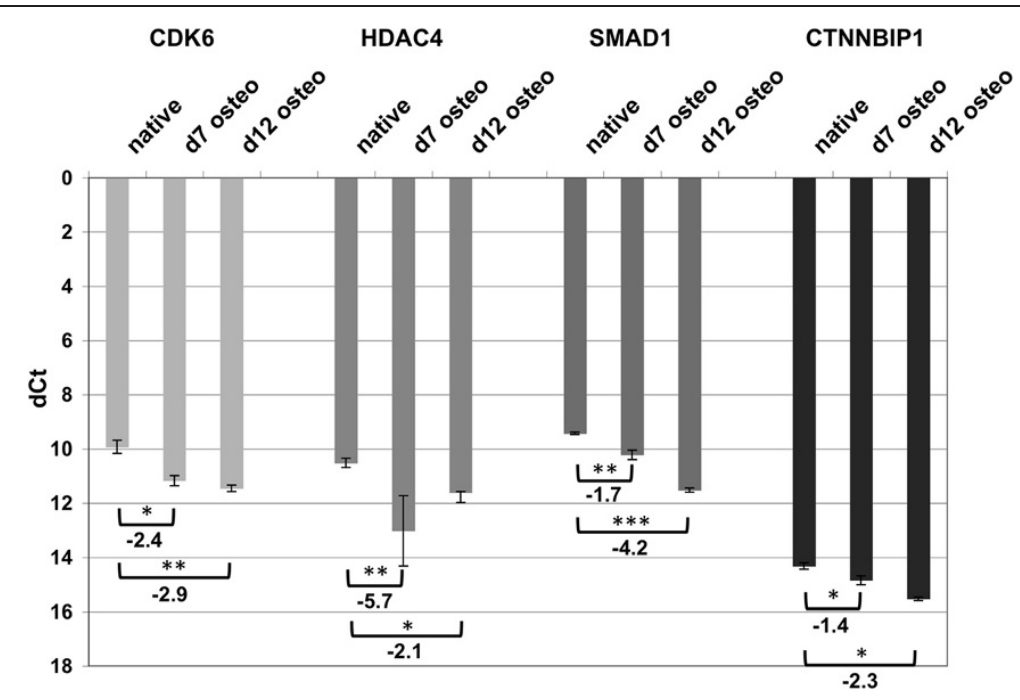

Figure 4 qPCR analysis of expression profiles of CDK6, HDAC4, SMAD1, and CTTNBIP1 during osteogenic differentiation of USSC 86b at days $\mathbf{0}$ (native), 7, and 12. B-actin normalized dCt values as means from 4 replicates are shown, together with standard deviation and statistical significancies (Student's $t$-test, unpaired, $: p \leq 0.05,{ }^{* *}: p \leq 0.01,{ }^{* * *}: p \leq 0.001$ ). Increased dCt values correspond to downregulation of transcripts during osteogenic differentiation and fold changes $\left(2^{- \text {ddct }}\right)$ in expression between native and differentiated cells are given for each transcript.

that both, miR-26a and miR-26b regulate SMAD1, this protein is known as a positive mediator of osteogenic differentiation [59]. We also identified the osteo-inhibitory BMP/SMAD regulator TOB1 [51] as a target of miR-26a and miR-26b. Substantial homology between these two miRNAs (identical seed sequences) is reflected in their similar behavior in our target validation assays. To clarify the contradictory roles of osteo-promoting SMAD1 and osteo-inhibitory CDK6 and TOB1 as parallel targets of miR-26a and miR-26b, we directly analyzed target protein abundance by quantitative Western blotting (i) during osteogenic differentiation of USSC and (ii) in response to transfection of USSC with miRNA mimics.

Despite targeting of the SMAD1 3'-UTR by miR-26a and miR-26b in our luciferase assay (Figure 3), SMAD1 protein abundance remained unaltered upon transfection with $\mathrm{miR}-26 \mathrm{a} / \mathrm{b}$ mimics (Figure 5F). This finding indicates either a long intracellular half-life for SMAD1 in USSC, unaltered by miRNA transfection in the experimental timeframe, or secondary regulatory mechanisms such as increased transcription that keep SMAD1 levels constant. Accordingly, SMAD1 protein levels also remained constant at day 9 in osteo-differentiated USSC 86b (Figure 5E) as expected for an osteo-promoting protein. However, our qPCR data indicate that SMAD1 transcription decreased steadily from day 0 to day 7 and to day 12 of osteogenic differentiation (Figure 4), further supporting a long halflife for SMAD1 protein. Due to strong calcification of USSC at day 12, we were unable to measure SMAD1 protein and it remains unclear whether this protein has a long half-life or is regulated by other unidentified mechanisms.
In contrast to osteo-promoting SMAD1, osteoinhibitory CDK6 protein expression was indeed reduced $48 \mathrm{~h}$ post transfection with miR-26a, miR-26b, and miR$29 \mathrm{~b}$ mimics. This finding indicates a comparatively strong regulatory influence of miR-26a/b and miR-29b on CDK6. However, despite steady transcript downregulation, CDK6 protein expression peaked at day 7 of osteogenic differentiation, before decreasing. As miRNAs act postranscriptionally $[4,60]$, the observed decrease of CDK6 abundance at day 12 was likely due to continued upregulation of miRNAs targeting osteo-inhibitory factors beyond day 7, after achieving sufficient levels to alter CDK6 protein abundance.

The HDAC4 gene product was reduced on both transcript (Figure 4) and protein level (Figure 5B) during osteogenic differentiation. Similarly, the HDAC4 protein level was reduced upon transfection with miR-29b mimic, consistent with our target validation assays. It should be noted that we were unable to detect either TOB1 transcripts or TOB1 and CTNNBIP1 gene products in USSC (data not shown).

Using alizarin-red staining and calcium release assays, we clearly demonstrated that miR-26a/b and miR-29b mimic transfections specifically accelerate osteogenic differentiation in both USSC lines tested. This result is consistent with the observation that miR-29b contributes to osteogenic differentiation of mouse osteoblasts [32]. It should be noted that attempts to functionally analyze miR-10a and miR-22 failed due to a nearly complete loss of transfected USSC from the culture plates (data not shown). 


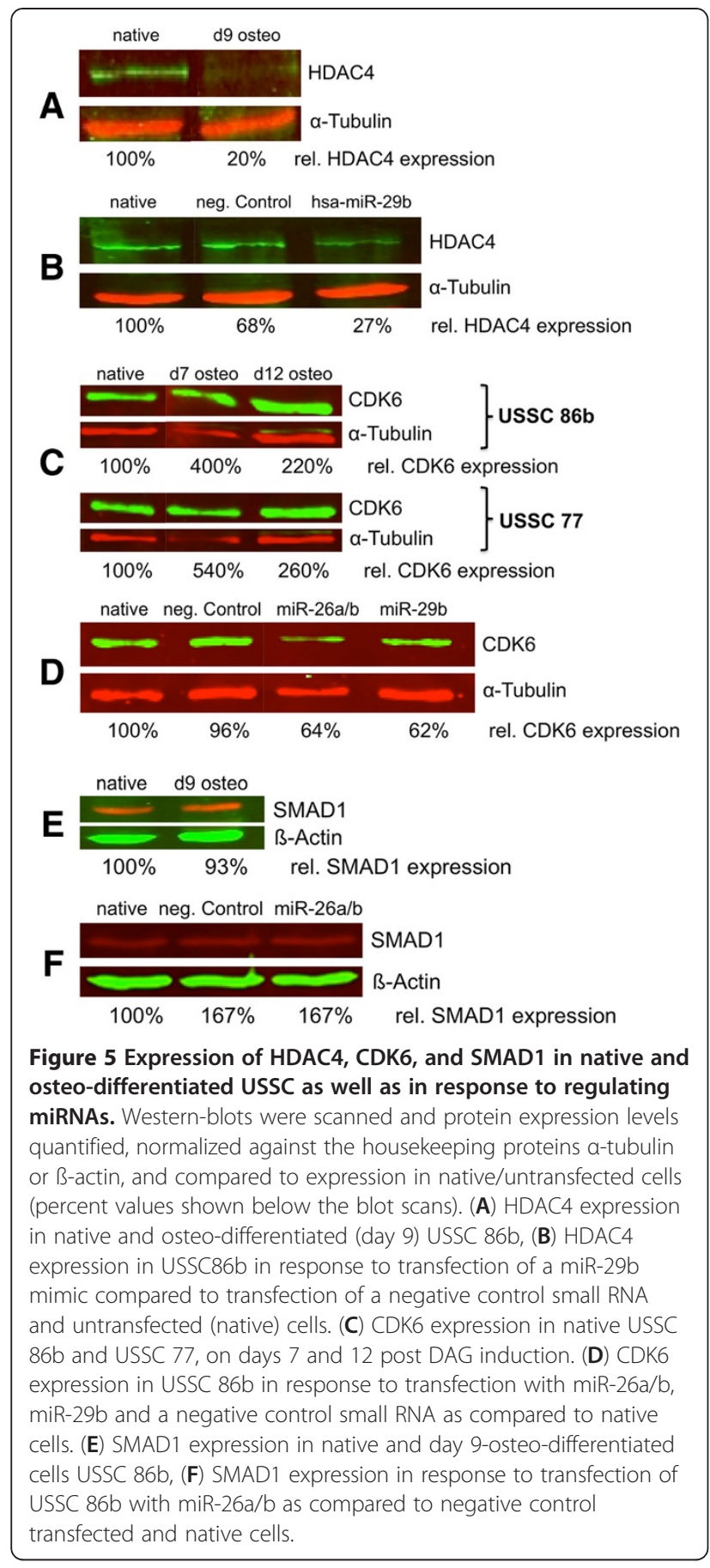

Since miR-26a/b and miR-29b regulate osteo-inhibitory and osteo-promoting factors in parallel, the osteo-inhibitory effects of CDK6 and HDAC4 likely outweigh the osteopromoting effects of SMAD1; this finding is further supported by the unaltered abundance of SMAD1 in miR$26 \mathrm{a} / \mathrm{b}$ transfected USSC.

The strongest effect on osteogenic differentiation was observed by transfecting an equimolar mixture of miR26a, miR-26b, and miR-29b mimics. It is likely that miR-
$26 \mathrm{a} / \mathrm{b}$ and miR-29b influence a common set of target genes with each miRNA making additional contributions through targeting exclusive genes e.g. HDAC4 and CTNNBIP1, which are regulated by miR-29b but not by $\mathrm{miR}-26 \mathrm{a} / \mathrm{b}$.

Recently miR-135b was reported to be 100 -fold upregulated in USSC following DAG-induction [61]. In contrast, $\mathrm{Li}$ and coworkers reported that miR-135b (and also miR-133a/b) were downregulated during mouse osteoblast differentiation after 16 hours [30]. In USSC, miR-133a and miR-133b as well as miR-135b are only weakly expressed even in native cells and virtually unchanged during osteogenic differentiation (see Additional file 1).

A recent study of miRNA expression signatures asssociated with osteogenic commitment of USSC showed upregulation of similar miRNAs (miR-26b, miR-30b, let$7 \mathrm{a}$, let-7f and miR-181a) as determined in our analysis [62]. However the authors used USSC from a different source, employed different miRNA expression analysis methodology (hybridisation array), and focused on other miRNAs, precluding direct comparison.

Taken together, our results further establish the importance of miRNAs in differentiation processes of USSC. We clearly demonstrated the combined functional impact of miR-26a/b and miR-29b, which had individually been identified as modulators of osteogenic differentiation in hADSC [31] and mouse osteoblasts [32]. Target gene similarities and differences between these miRNAs imply that these miRNAs act in a synergistic manner to improve and accelerate osteogenic differentiation of USSC.

\section{Conclusions}

In summary, we detected a subset of miRNAs, notably miR-26a, miR-26b and miR-29b, which is consistently upregulated during osteogenic differentiation of USSC. We experimentally identified specific osteo-inhibitory proteins as regulatory targets for these miRNAs in reporter gene analyses and in direct measurements of target protein abundance. Functional analyses demonstrated that miR-26a, miR-26b and miR-29b positively modulate osteogenic differentiation of USSC, most likely by downregulating osteo-inhibitory target proteins. Together with our previous studies on neuronal lineage differentiation [38], [39] these findings further support the notion that differentiation of the unique somatic stem cell type USSC follows established biochemical pathways wherein miRNAs are important regulatory molecules.

\section{Methods}

\section{Generation and osteogenic lineage differentiation of USSC}

USSC lines were isolated from human cord blood and characterized in a designated unit in our institute under GMP conditions as described in detail in [33] and [63] 




and were supplied to us for this study. Informed consent was obtained from each participant.

USSC lines SA5/73 and SA8/25 were induced to osteogenic differentiation on addition of DAG (dexamethasone, ascorbic acid, ß-glycerolphosphate). Cells were incubated for 7 days and osteogenic differentiation was assessed using Alizarin-Red staining as described [33]. Calcium release was measured following incubation of cells in $6 \mathrm{M}$ $\mathrm{HCl}$ for $24 \mathrm{~h}$ at $37^{\circ} \mathrm{C}$; calcium content in the supernatant was analyzed using the Calcium Colorimetric Assay (BioVision) according to the manufacturer's instructions followed by normalization to the protein content of the sample.

\section{miRNA expression analysis}

Small and large RNA fractions were isolated from native and differentiated USSC lines SA5/73 and SA8/25 using the Ambion mirVana miRNA Isolation kit (Applied Biosystems, Darmstadt, FRG) according to the manufacturer's instructions; adherent USSC were directly lysed without cell trypsinization. Total RNA for small RNA sequencing was prepared using TRIzol reagent (Invitrogen, FRG).

miRNA expression analyses were performed on small RNA fractions using the TaqMan miRNA Megaplex array (pool A, Applied Biosystems, Darmstadt, FRG) [43] according to the manufacturer's instructions. Briefly, 10ng 

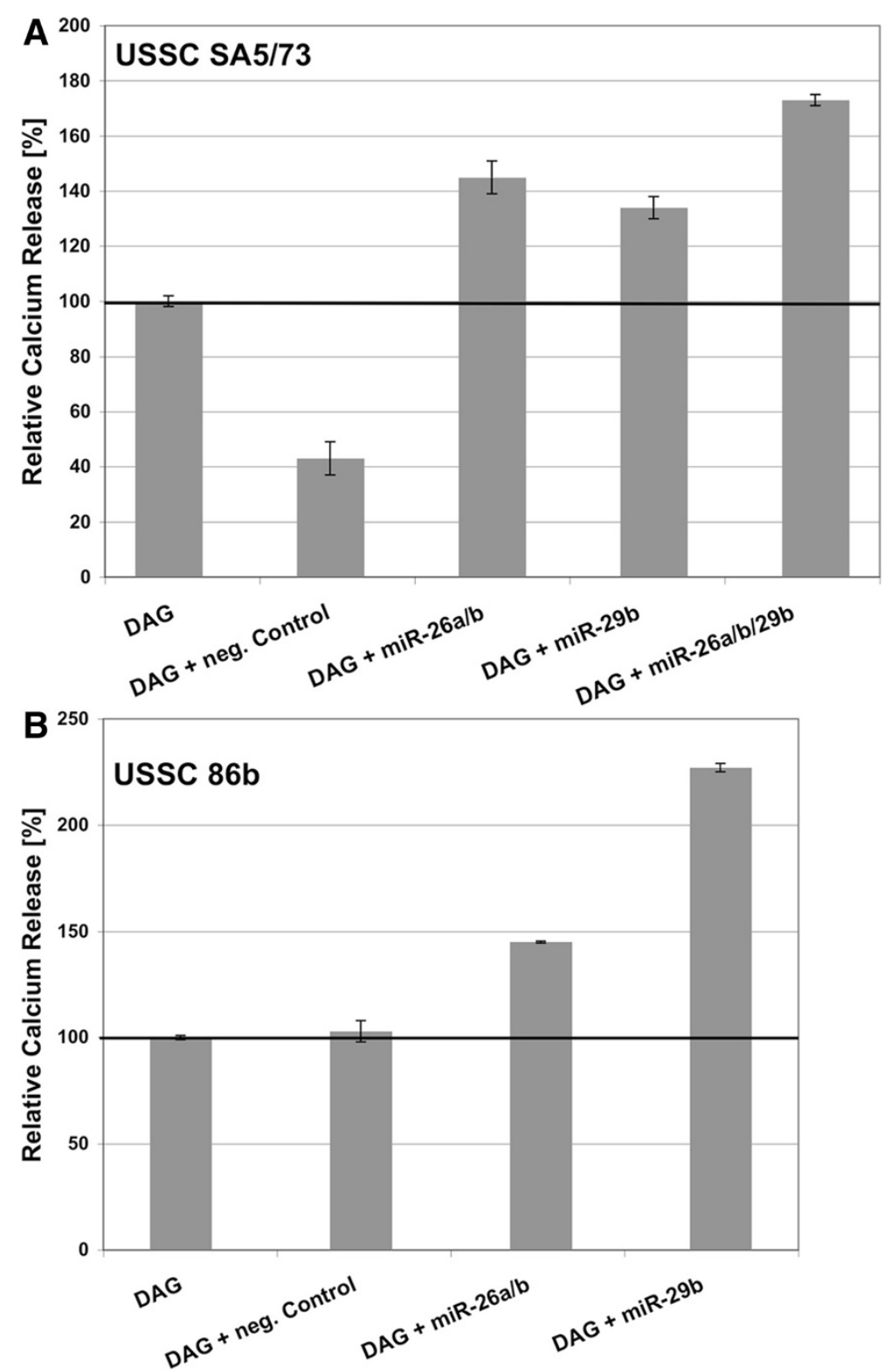

Figure 7 Calcium-release assay from cells used in functional assays described in Figure 5. (A) USSC SA5/73, (B) USSC 86b. Percent mean values from experimental duplicates are given. In both cell lines, calcium release increased upon transfection with miR-26a/b and miR-29b followed by DAG-induction, as compared with untransfected/neg. control-transfected cells.

small RNA fraction was reverse transcribed and preamplified for 12 PCR cycles, with subsequent TaqMan-probe based array-amplification for 40 additional PCR cycles. Raw Ct-values were normalized to U6 RNA data and ddCt as well as $2^{-(\mathrm{ddCt})}$ data were calculated.

Barcoded small RNA sequencing was used to generate miRNA expression profiles for four native USSC lines (SA5/73, SA8/25, SA8/77, SA4/101) and two day 7-osteo -differentiated USSC lines (SA8/77 and SA4/101); this method is a modification of an established small RNA sequencing protocol which involves sequential ligation of $3^{\prime}$ and $5^{\prime}$ adapters to small RNAs, followed by cDNA library preparation, Solexa sequencing, and small RNA annotation [56].

\section{Bioinformatic target gene predictions}

Most miRNA targets were predicted using the miRGen engine (http://www.diana.pcbi.upenn.edu/miRGen.html); additional targets were identified using miRanda (http:// www.microrna.org/microrna/getGeneForm.do), PicTar (http://pictar.mdc-berlin.de/), and TargetScan webtools (http://www.targetscan.org/). Further analyses (gene ontology) of predicted targets were performed using the DAVID database (http://david.abcc.ncifcrf.gov/home.jsp). 


\section{Experimental verification of bioinformatic target gene predictions}

PCR-products of full length or fragments of $3^{\prime}$-UTRs as well as double-stranded oligonucleotides covering the predicted miRNA binding sites on the target mRNA of interest were cloned at the $3^{\prime}$-end of firefly luciferase ORF in dual reporter (firefly and renilla luciferases) vector pmirGLO (GenBank accession FJ376737, Promega Mannheim, FRG) using restriction enzyme pairs SacI/ XbaI or SalI/Xhol. PCR primers, sense and antisense oligonucleotides, and 3 '-UTR- and fragment-lengths are listed in Additional file 3. To normalize for effects of endogenous miRNAs on a given $3^{\prime}$-UTR, 100ng pmirGLO and pmirGLO/3'-UTR were transfected into $5 \times 10^{4}$ HEK293T cells using $0.5 \mu$ l Lipofectamine 2000 (Invitrogen, Karlsruhe, FRG). Pairwise cotransfections of 100ng empty pmirGLO with the $2.5 \mathrm{pmol}$ miRNA mimic (Dharmacon, Bonn, FRG) of interest and pmirGLO/3'UTR with the miRNA mimic of interest were performed to determine the influence of the given miRNA on the $3^{\prime}$ UTR. Firefly and renilla activities were measured $24 \mathrm{~h}$ after transfection using Beetlejuice and Renillajuice reagents (PJK, Kleinblittersdorf, FRG). All transfection experiments were performed in at least two independent biological experiments with quadruple transfections each and statistical significances were calculated by a student's t-test, unpaired.

\section{Real-time PCR analysis}

Total RNA was isolated using Trizol reagent (Invitrogen) according to the manufacturer's instructions. RNAs were reverse transcribed using M-MLV reverse transcriptase (Promega, Mannheim, FRG) and real-time PCRs were performed using the Maxima SYBR Green/ROX qPCR Master Mix (Fermentas, St. Leon-Rot, FRG). Primers for CDK6 [64], CTNNBIP1 [65], SMAD1 [31] and HDAC4 (this work) used in RT-reactions are listed in Additional file 3. Results were analyzed using Step One Software v2.1 and statistical significances were calculated by a student's t-test, unpaired.

\section{Transfections of USSC for Western blots and functional analyses}

To analyze changes in endogenous protein abundance during osteogenesis, USSC were cultivated on 6-well plates and induced with DAG as described above. Proteins were isolated at days 0 (native), 7, 9, and 12 . To evaluate the impact of miRNAs on endogenous target proteins, USSC were cultivated on 6-well plates and transfected with 40pmol of relevant miRNA-mimic/well using Dharmafect1 reagent according to the manufacturer's instructions, proteins were isolated $48 \mathrm{~h}$ after transfection. Native, osteo-differentiated and transfected USSC were washed with PBS and lysed using RIPA-Buffer (Sigma, FRG) supplemented with protease inhibitor cocktail tablets (Roche, FRG). Up to $50 \mu \mathrm{g}$ of proteins/lane were separated by SDS-PAA electrophoresis, blotted onto nitrocellulose membranes $(0.45 \mu \mathrm{m})$, and membranes were blocked with $3 \%$ Milk/PBS, incubated with primary antibodies (see below) in 3\% milk/PBS followed by incubation with the appropiate secondary antibody (see below) in 3\% milk/PBS/0,15\% Tween-20. Membranes were washed in PBS-T/0.1\% Tween-20, dried, and scanned with the LI-COR Odyssey Infrared Imager (LI-COR Biosystems). Visible false-color signals were quantified using Odyssey 2.1 software (LI-COR Biosystems) and normalized against signals from quantified housekeeping proteins $\alpha$-Tubulin or $\beta$-Actin. The following antibodies were used in this study: CDK6, sc-177; HDAC4, sc-11418; SMAD1, sc-7965 (all Santa Cruz Biotechnology), $\alpha$-Tubulin, B-5-1-2 (Sigma Aldrich); B-Actin, ab34731 (abcam); IRDye 680LT $\alpha$-mouse and IRDye $800 \mathrm{CW} \alpha$-rabbit (both: LI-COR Biosystems).

For functional analyses, USSC were cultivated on 24-well plates and transfected with 10pmol miRNA-mimic/well using Dharmafect1 reagent according to the manufacturer's instructions. Transfected cells were induced to osteogenic differentiation $24 \mathrm{~h}$ post transfection as described above. Differentiation was analyzed at day 7 by alizarin-red stainig and calcium released as described above.

\section{Ethics statement}

Work with USSC was approved by the Ethics Committee of the Medical Faculty, University Düsseldorf, study numbers 3436 and 2975.

\section{Additional files}

Additional file 1: Comprehensive miRNA expression data from native (d0) USSC SA5/73 and SA8/25 and osteo-differentiated (day 7) $S A 5 / 73$ and $S A 8 / 25$. This Excel file contains three separate sheets, "USSC SA573", "USSC SA825", and "Deep Sequencing". In the first two, raw Ct, U6-RNA normalized dCt, ddCt, and $2^{- \text {ddCt }}$ values (corresponding to fold changes of miRNA expression in day 7 osteo vs. native cells, in grey columns) are given for each miRNA analyzed. The sheet "deep sequencing" indicates results from deep-sequencing derived expression analysis of miR-26a and miR-26b in native USSC SA5/73, SA8/25, SA8/77, and SA4/101 and osteo-differentiated USSC SA8/77 and SA4/101. Total sequence reads for the miRNA indicated as well as frequency of specific sequence reads among all sequence reads are given.

Additional file 2: Experimental validation of miRNA target gene predictions. Detailed data of validations of CTNNBIP1 (A), DUSP2 (B), HDAC4-1 (C), HDAC4-O1 and HDAC4-O2 (D), SMAD1 (E), SMAD6 (F), TGFB3 $(G)$, and TOB1 $(H)$ are given. The bar above the graphs depict the respective $3^{\prime}$-UTRs, with the blue part representing the analyzed fragment, including putative miRNA binding sites. For further description see Figure 2

Additional file 3: Primers and oligonucleotides. This Excel file summarizes primers and sense- and antisense-oligonucleotides used for 3'-UTR cloning and qRT-PCR analysis. Sheet " 3 'UTR cloning": Primers for generation of PCR products from $3^{\prime}$-UTRs, corresponding NCBI accession numbers, and sense- and antisense-oligonucleotides used for experimental target validation of predicted target proteins. Restriction 
sites used for cloning are given in bold as well as sticky and recessed ends synthesized into oligonucleotides. " $\odot$ " denotes the phosphate group added to the $5^{\prime}$-end of oligonucleotides. Mutations in oligonucleotide sequences corresponding to the seed of microRNAs are given in red. Sheet "qRT-PCR": Forward and reverse primers used for RTreaction.

\section{Competing interests}

The authors declare that they have no competing interests.

\section{Authors' contributions}

HIT conceived and supervised the study, participated in molecular biology and protein biology experiments and wrote the manuscript. JD performed all miRNA analyses including bioinformatics, target validations and functional experiments. EH carried out all Western blot experiments. KMI delivered RTPCR based miRNA expression analyses, NR, MH, and TT delivered deep sequencing data, and PW supervised the study. All authors read and approved the final manuscript.

\section{Acknowledgements}

We are indebted to Gesine Kögler (ITZ) and Anja Buchheiser (ITZ) for USSC cell supply and to Daniela Stapelkamp (ITZ) for assistance in osteogenic differentiation of USSC

\section{Funding information}

This work was supported by a grant from the Deutsche Forschungsgemeinschaft (DFG Research Group FOR717 WE505/2-1) given to PW and HIT and by a grant from the Bundesministerium für Bildung und Forschung (BMBF) given to PW (DLR/BMBF 01GN1008A). NR is supported through a K08 award (NS072235) from the National Institute of Neurologica Disorders and Stroke. $\mathrm{MH}$ is supported by a fellowship from the Charles $\mathrm{H}$. Revson, Jr. Foundation.

\section{Author details}

'University Düsseldorf, Medical Faculty, Institute for Transplantation Diagnostics and Cell Therapeutics (ITZ), Düsseldorf D-40225, Germany. ${ }^{2}$ Howard Hughes Medical Institute, Laboratory of RNA Molecular Biology, Rockefeller University, New York, NY 10065, USA.

Received: 21 September 2012 Accepted: 7 February 2013 Published: 19 February 2013

\section{References}

1. Yi R, Qin Y, Macara IG, Cullen BR: Exportin-5 mediates the nuclear export of pre-microRNAs and short hairpin RNAs. Genes Dev 2003, 17(24):3011-3016.

2. Lee Y, Ahn C, Han J, Choi H, Kim J, Yim J, Lee J, Provost P, Radmark O, Kim $\mathrm{S}$, et al: The nuclear RNase III Drosha initiates microRNA processing. Nature 2003, 425(6956):415-419.

3. Schwarz DS, Hutvagner G, Du T, Xu Z, Aronin N, Zamore PD: Asymmetry in the assembly of the RNAi enzyme complex. Cell 2003, 115(2):199-208.

4. Bartel DP: MicroRNAs: genomics, biogenesis, mechanism, and function. Cell 2004, 116(2):281-297.

5. Lewis BP, Burge CB, Bartel DP: Conserved seed pairing, often flanked by adenosines, indicates that thousands of human genes are microRNA targets. Cell 2005, 120(1):15-20.

6. Gebauer F, Hentze MW: Molecular mechanisms of translational control. Nat Rev Mol Cell Biol 2004, 5(10):827-835

7. Lim LP, Lau NC, Garrett-Engele P, Grimson A, Schelter JM, Castle J, Bartel DP, Linsley PS, Johnson JM: Microarray analysis shows that some microRNAs downregulate large numbers of target mRNAs. Nature 2005 433(7027):769-773.

8. Lagos-Quintana M, Rauhut R, Yalcin A, Meyer J, Lendeckel W, Tuschl T: Identification of tissue-specific microRNAs from mouse. Curr Biol 2002, 12(9):735-739.

9. Sempere LF, Freemantle S, Pitha-Rowe I, Moss E, Dmitrovsky E, Ambros V: Expression profiling of mammalian microRNAs uncovers a subset of brain-expressed microRNAs with possible roles in murine and human neuronal differentiation. Genome Biol 2004, 5(3):R13.
10. Xu P, Vernooy SY, Guo M, Hay BA: The Drosophila microRNA Mir-14 suppresses cell death and is required for normal fat metabolism. Curr Biol 2003, 13(9):790-795.

11. Subramanian S, Steer CJ: MicroRNAs as gatekeepers of apoptosis. J Cell Physiol, 223(2):289-298

12. Shenouda SK, Alahari SK: MicroRNA function in cancer: oncogene or a tumor suppressor? Cancer Metastasis Rev 2009, 28(3-4):369-378.

13. Brennecke J, Hipfner DR, Stark A, Russell RB, Cohen SM: bantam encodes a developmentally regulated microRNA that controls cell proliferation and regulates the proapoptotic gene hid in Drosophila. Cell 2003, 113(1):25-36.

14. Giraldez AJ, Cinalli RM, Glasner ME, Enright AJ, Thomson JM, Baskerville S, Hammond SM, Bartel DP, Schier AF: MicroRNAs regulate brain morphogenesis in zebrafish. Science 2005, 308(5723):833-838.

15. Naguibneva I, Ameyar-Zazoua M, Polesskaya A, Ait-Si-Ali S, Groisman R, Souidi M, Cuvellier S, Harel-Bellan A: The microRNA miR-181 targets the homeobox protein Hox-A11 during mammalian myoblast differentiation. Nat Cell Biol 2006, 8(3):278-284.

16. Xu N, Papagiannakopoulos T, Pan G, Thomson JA, Kosik KS: MicroRNA-145 regulates OCT4, SOX2, and KLF4 and represses pluripotency in human embryonic stem cells. Cell 2009, 137(4):647-658.

17. Komori T: Regulation of osteoblast differentiation by transcription factors. J Cell Biochem 2006, 99(5):1233-1239.

18. Lian JB, Stein GS, Javed A, van Wijnen AJ, Stein JL, Montecino M, Hassan MQ Gaur T, Lengner CJ, Young DW: Networks and hubs for the transcriptional control of osteoblastogenesis. Rev Endocr Metab Disord 2006, 7(1-2):1-16.

19. Rodan GA: Introduction to bone biology. Bone 1992, 13(Suppl 1):S3-6.

20. Olsen BR, Reginato AM, Wang W: Bone development. Annu Rev Cell Dev Biol 2000, 16:191-220.

21. Gordeladze JO, Djouad F, Brondello JM, Noel D, Duroux-Richard I, Apparailly $\mathrm{F}$, Jorgensen C: Concerted stimuli regulating osteo-chondral differentiation from stem cells: phenotype acquisition regulated by microRNAs. Acta Pharmaco/ Sin 2009, 30(10):1369-1384.

22. Bodine PV, Komm BS: Wnt signaling and osteoblastogenesis. Rev Endocr Metab Disord 2006, 7(1-2):33-39.

23. Deng ZL, Sharff KA, Tang N, Song WX, Luo J, Luo X, Chen J, Bennett E, Reid $\mathrm{R}$, Manning $\mathrm{D}$, et al: Regulation of osteogenic differentiation during skeletal development. Front Biosci 2008, 13:2001-2021.

24. Gaur T, Lengner CJ, Hovhannisyan H, Bhat RA, Bodine PV, Komm BS, Javed A, van Wijnen AJ, Stein JL, Stein GS, et al: Canonical WNT signaling promotes osteogenesis by directly stimulating Runx2 gene expression. J Biol Chem 2005, 280(39):33132-33140.

25. Ge C, Xiao G, Jiang D, Franceschi RT: Critical role of the extracellular signal-regulated kinase-MAPK pathway in osteoblast differentiation and skeletal development. J Cell Biol 2007, 176(5):709-718.

26. Levy JB, Schindler C, Raz R, Levy DE, Baron R, Horowitz MC: Activation of the JAK-STAT signal transduction pathway by oncostatin-M cultured human and mouse osteoblastic cells. Endocrinology 1996, 137(4):1159-1165.

27. Bandyopadhyay A, Tsuji K, Cox K, Harfe BD, Rosen V, Tabin CJ: Genetic analysis of the roles of BMP2, BMP4, and BMP7 in limb patterning and skeletogenesis. PLoS Genet 2006, 2(12):e216

28. Mohri T, Nakajima M, Takagi S, Komagata S, Yokoi T: MicroRNA regulates human vitamin D receptor. Int J Cancer 2009, 125(6):1328-1333.

29. Mizuno Y, Yagi K, Tokuzawa Y, Kanesaki-Yatsuka Y, Suda T, Katagiri T, Fukuda T, Maruyama M, Okuda A, Amemiya T, et al: miR-125b inhibits osteoblastic differentiation by down-regulation of cell proliferation. Biochem Biophys Res Commun 2008, 368(2):267-272.

30. Li Z, Hassan MQ, Volinia S, van Wijnen AJ, Stein JL, Croce CM, Lian JB, Stein GS: A microRNA signature for a BMP2-induced osteoblast lineage commitment program. Proc Natl Acad Sci U S A 2008, 105(37):13906-13911.

31. Luzi E, Marini F, Sala SC, Tognarini I, Galli G, Brandi ML: Osteogenic differentiation of human adipose tissue-derived stem cells is modulated by the miR-26a targeting of the SMAD1 transcription factor. J Bone Miner Res 2008, 23(2):287-295.

32. Li Z, Hassan MQ Jafferii M, Aqeilan Rl, Garzon R, Croce CM, van Wijnen AJ, Stein JL, Stein GS, Lian JB: Biological functions of miR-29b contribute to positive regulation of osteoblast differentiation. J Biol Chem 2009 284(23):15676-15684

33. Kogler G, Sensken S, Airey JA, Trapp T, Muschen M, Feldhahn N, Liedtke S, Sorg RV, Fischer J, Rosenbaum C, et al: A new human somatic stem cell from placental cord blood with intrinsic pluripotent differentiation potential. J Exp Med 2004, 200(2):123-135. 
34. Liedtke S, Buchheiser A, Bosch J, Bosse F, Kruse F, Zhao X, Santourlidis S, Kogler G: The HOX Code as a "biological fingerprint" to distinguish functionally distinct stem cell populations derived from cord blood. Stem Cell Res 2010, 5(1):40-50.

35. Wernet $P$, Trapp $T$, Z weigerdt $R$, Mann J, Trompeter HI: Lentiviral labeling reveals three germ layer differentiation potential of a single unrestricted somatic stem cell from human cord blood. Exp Hematol 2010, 38(11):1099-1104.

36. Zaehres H, Kogler G, Arauzo-Bravo MJ, Bleidissel M, Santourlidis S, Weinhold S, Greber B, Kim JB, Buchheiser A, Liedtke S, et al: Induction of pluripotency in human cord blood unrestricted somatic stem cells. Exp Hematol 2010, 38(9):809-818. 818 e801-802.

37. Greschat S, Schira J, Kury P, Rosenbaum C, de Souza Silva MA, Kogler G, Wernet $P$, Muller HW: Unrestricted somatic stem cells from human umbilical cord blood can be differentiated into neurons with a dopaminergic phenotype. Stem Cells Dev 2008, 17(2):221-232.

38. Iwaniuk KM, Schira J, Weinhold S, Jung M, Adjaye J, Müller HW, Wernet $P$, Trompeter H-l: Network-like Impact of MicroRNAs on Neuronal Lineage Differentiation of Unrestricted Somatic Stem Cells from Human Cord Blood (USSC). Stem Cells Dev 2011, 20(8):1383-1394.

39. Trompeter HI, Abbad H, Iwaniuk KM, Hafner M, Renwick N, Tuschl T, Schira J, Muller HW, Wernet P: MicroRNAs MiR-17, MiR-20a, and MiR-106b Act in Concert to Modulate E2F Activity on Cell Cycle Arrest during Neuronal Lineage Differentiation of USSC. PLoS One 2011, 6(1):e16138.

40. Sensken S, Waclawczyk S, Knaupp AS, Trapp T, Enczmann J, Wernet P, Kogler G: In vitro differentiation of human cord blood-derived unrestricted somatic stem cells towards an endodermal pathway. Cytotherapy 2007, 9(4):362-378

41. Waclawczyk S, Buchheiser A, Flogel U, Radke TF, Kogler G: In vitro differentiation of unrestricted somatic stem cells into functional hepaticlike cells displaying a hepatocyte-like glucose metabolism. J Cell Physiol 2010, 225(2):545-554

42. Schira J, Gasis M, Estrada V, Hendricks M, Schmitz C, Trapp T, Kruse F, Kogler $G$, Wernet $P$, Hartung HP, et al: Significant clinical, neuropathological and behavioural recovery from acute spinal cord trauma by transplantation of a well-defined somatic stem cell from human umbilical cord blood. Brain 2012, 135(2):431-446.

43. Chen C, Ridzon DA, Broomer AJ, Zhou Z, Lee DH, Nguyen JT, Barbisin M, Xu $\mathrm{NL}$, Mahuvakar VR, Andersen MR, et al: Real-time quantification of microRNAs by stem-loop RT-PCR. Nucleic Acids Res 2005, 33(20):e179.

44. Megraw M, Sethupathy P, Corda B, Hatzigeorgiou AG: miRGen: a database for the study of animal microRNA genomic organization and function. Nucleic Acids Res 2007, 35(Database issue):D149-155.

45. Grossel MJ, Hinds PW: Beyond the cell cycle: a new role for Cdk6 in differentiation. J Cell Biochem 2006, 97(3):485-493.

46. Ogasawara T, Kawaguchi H, Jinno S, Hoshi K, Itaka K, Takato T, Nakamura K, Okayama H: Bone morphogenetic protein 2-induced osteoblast differentiation requires Smad-mediated down-regulation of Cdk6. $\mathrm{Mol}$ Cell Biol 2004, 24(15):6560-6568.

47. Ogasawara T, Katagiri M, Yamamoto A, Hoshi K, Takato T, Nakamura K, Tanaka S, Okayama H, Kawaguchi H: Osteoclast differentiation by RANKL requires NF-kappaB-mediated downregulation of cyclin-dependent kinase 6 (Cdk6). J Bone Miner Res 2004, 19(7):1128-1136.

48. Daniels DL, Weis WI: ICAT inhibits beta-catenin binding to Tcf/Lef-family transcription factors and the general coactivator p300 using independent structural modules. Mol Cell 2002, 10(3):573-584.

49. Jeon EJ, Lee KY, Choi NS, Lee MH, Kim HN, Jin YH, Ryoo HM, Choi JY, Yoshida M, Nishino N, et al: Bone morphogenetic protein-2 stimulates Runx2 acetylation. J Biol Chem 2006, 281(24):16502-16511.

50. Caunt CJ, Rivers CA, Conway-Campbell BL, Norman MR, McArdle CA: Epidermal growth factor receptor and protein kinase $C$ signaling to ERK2: spatiotemporal regulation of ERK2 by dual specificity phosphatases. J Biol Chem 2008, 283(10):6241-6252.

51. Yoshida Y, Tanaka S, Umemori H, Minowa O, Usui M, Ikematsu N, Hosoda E, Imamura T, Kuno J, Yamashita $T$, et al: Negative regulation of BMP/Smad signaling by Tob in osteoblasts. Cell 2000, 103(7):1085-1097.

52. Kang JS, Alliston T, Delston R, Derynck R: Repression of Runx2 function by TGF-beta through recruitment of class II histone deacetylases by Smad3. EMBO J 2005, 24(14):2543-2555.

53. Maeda S, Hayashi M, Komiya S, Imamura T, Miyazono K: Endogenous TGFbeta signaling suppresses maturation of osteoblastic mesenchymal cells. EMBO J 2004, 23(3):552-563.
54. Hata A, Lagna G, Massague J, Hemmati-Brivanlou A: Smad6 inhibits BMP/ Smad1 signaling by specifically competing with the Smad4 tumor suppressor. Genes Dev 1998, 12(2):186-197.

55. Sowa H, Kaji H, Hendy GN, Canaff L, Komori T, Sugimoto T, Chihara K: Menin is required for bone morphogenetic protein 2- and transforming growth factor beta-regulated osteoblastic differentiation through interaction with Smads and Runx2. J Biol Chem 2004, 279(39):40267-40275.

56. Hafner $M$, Landgraf $P$, Ludwig J, Rice A, Ojo T, Lin C, Holoch D, Lim C, Tuschl T: Identification of microRNAs and other small regulatory RNAs using cDNA library sequencing. Methods 2008, 44(1):3-12.

57. Hafner M, Renwick N, Brown M, Mihailovic A, Holoch D, Lin C, Pena JT, Nusbaum JD, Morozov P, Ludwig J, et al: RNA-ligase-dependent biases in miRNA representation in deep-sequenced small RNA cDNA libraries. RNA 2011, 17(9):1697-1712

58. Cloonan N, Brown MK, Steptoe AL, Wani S, Chan WL, Forrest AR, Kolle G, Gabrielli B, Grimmond SM: The miR-17-5p microRNA is a key regulator of the G1/S phase cell cycle transition. Genome Biol 2008, 9(8):R127.

59. Ju W, Hoffmann A, Verschueren K, Tylzanowski P, Kaps C, Gross G, Huylebroeck D: The bone morphogenetic protein 2 signaling mediator Smad1 participates predominantly in osteogenic and not in chondrogenic differentiation in mesenchymal progenitors $\mathrm{C} 3 \mathrm{H} 10 \mathrm{~T} 1 / 2$. J Bone Miner Res 2000, 15(10):1889-1899.

60. Bartel DP: MicroRNAs: target recognition and regulatory functions. Cell 2009, 136(2):215-233.

61. Schaap-Oziemlak AM, Raymakers RA, Bergevoet SM, Gilissen C, Jansen BJ, Adema GJ, Kogler G, le Sage C, Agami R, van der Reijden BA, et al: MicroRNA hsa-miR-135b regulates mineralization in osteogenic differentiation of human unrestricted somatic stem cells. Stem Cells Dev 2010, 19(6):877-885.

62. Bakhshandeh B, Soleimani M, Hafizi M, Paylakhi SH, Ghaemi N: MicroRNA signature associated with osteogenic lineage commitment. Mol Biol Rep 2012, 39(7):7569-7581

63. Aktas M, Buchheiser A, Houben A, Reimann V, Radke T, Jeltsch K, Maier P, Zeller WJ, Kogler G: Good manufacturing practice-grade production of unrestricted somatic stem cell from fresh cord blood. Cytotherapy 2010, 12(3):338-348

64. Xie L, Wei J, Qian X, Chen G, Yu L, Ding Y, Liu B: CXCR4, a potential predictive marker for docetaxel sensitivity in gastric cancer. Anticancer Res 2010, 30(6):2209-2216.

65. Reifenberger J, Knobbe CB, Wolter M, Blaschke B, Schulte KW, Pietsch T, Ruzicka T, Reifenberger G: Molecular genetic analysis of malignant melanomas for aberrations of the WNT signaling pathway genes CTNNB1, APC, ICAT and BTRC. Int J Cancer 2002, 100(5):549-556.

doi:10.1186/1471-2164-14-111

Cite this article as: Trompeter et al.: MicroRNAs miR-26a, miR-26b, and miR$29 \mathrm{~b}$ accelerate osteogenic differentiation of unrestricted somatic stem cells from human cord blood. BMC Genomics 2013 14:111.

\section{Submit your next manuscript to BioMed Central and take full advantage of:}

- Convenient online submission

- Thorough peer review

- No space constraints or color figure charges

- Immediate publication on acceptance

- Inclusion in PubMed, CAS, Scopus and Google Scholar

- Research which is freely available for redistribution 